\title{
Influence of Grain Boundary on the Fatigue Crack Growth of 7050-T7451 Aluminum Alloy Based on Small Time Scale Method
}

\author{
Weihan Wang, Weifang Zhang, Hongxun Wang, Xiaoliang Fang, and Xiaobei Liang \\ Science \& Technology on Reliability \& Environmental Engineering Laboratory, Beihang University, Beijing 100191, China \\ Correspondence should be addressed to Weifang Zhang; 08590@buaa.edu.cn
}

Received 25 March 2016; Accepted 16 June 2016

Academic Editor: Liviu Marsavina

Copyright ( 2016 Weihan Wang et al. This is an open access article distributed under the Creative Commons Attribution License, which permits unrestricted use, distribution, and reproduction in any medium, provided the original work is properly cited.

\begin{abstract}
Based on the small time scale method, the influence of grain boundary on the fatigue crack growth of 7050-T7451 has been investigated. The interaction between fatigue crack and grain boundary was investigated by in situ SEM testing. Results showed that the fatigue crack growth will be retarded by grain boundary when the angle between fatigue crack and grain boundary is greater than 90 degrees. Mechanism analysis showed that the fatigue crack tip would not be able to open until the loading reached the $55 \%$ of maximum load, and the fatigue crack had been closed completely before the loading was not reduced to the minimum value, which led to the crack growth retardation. When the 7050-T7451 aluminum alloy suffered from fatigue loading with constant amplitude, a behavior of unstable fatigue crack growth could be observed often, and results indicated that the bridge linked mechanism led to the behavior. The grain boundary was prone to fracture during fatigue loading, and it became the best path for the fatigue crack growth. The fatigue crack tip would be connected with fractured grain boundary eventually, which led to the fast crack growth in different loading stage.
\end{abstract}

\section{Introduction}

7050-T7451 is a kind of high strength aluminum alloy which has been widely used in aerospace fields for its excellent properties, such as high specific strength, good fracture toughness, and stress corrosion resistance $[1,2]$. Due to the fact that the aircraft bears complicated loadings in service, including maneuver loading, gust loading, and ground loading, the accumulation of fatigue damage will appear in the structure of 7050-T7451 aluminum alloy, which may lead to the fatigue fracture and cause disastrous accidents.

In essence, the fatigue fracture of 7050-T7451 aluminium alloy is the process of microdefect's initiation and growth. Microstructure such as grain boundary and second phase play an important role in the fatigue crack growth. Researchers found that the plastic deformation of metallic materials was seriously influenced by the grain boundary. Kamp et al. [3] observed that the transgranular propagation of persistent slip bands was impeded by the grain boundary and the fatigue crack tended to grow along grain boundaries or subgrain boundaries. Scharnweber et al. [4] analyzed the effect of grain boundary on small crack growth in stainless steel, and results showed that the hindering effect of grain boundary on fatigue crack growth is mainly affected by the plastic area of crack tip. Holzapfel et al. [5] found that the subsurface orientation of grain boundaries is an important factor for interpreting crack growth rate at the surface. Terentyev and Gao [6] demonstrated that both low and high angle grain boundaries exhibit resistance to brittle crack propagation. Wang and Dong [7] indicated that the precipitation of carbide at grain boundary strengthened the grain boundary and decreased the crack growth rate.

At present, the researches for the effect of grain boundary on the fatigue crack growth are mainly focused on the fracture analysis and in situ testing [8-10]. The fracture analysis could be used for analyzing the damage mechanism; however, the deformation process during the loading period is hardly reflected and it limits the recognition of damage mechanism. The in situ testing is able to observe the whole process of fatigue crack growth in real time; however, existing methods mainly focused on the research of damage mechanism between hundreds or thousands of loading cycles, and seldom studies focused on the behavior of fatigue crack growth within one loading cycle. Recently, a method of small time 


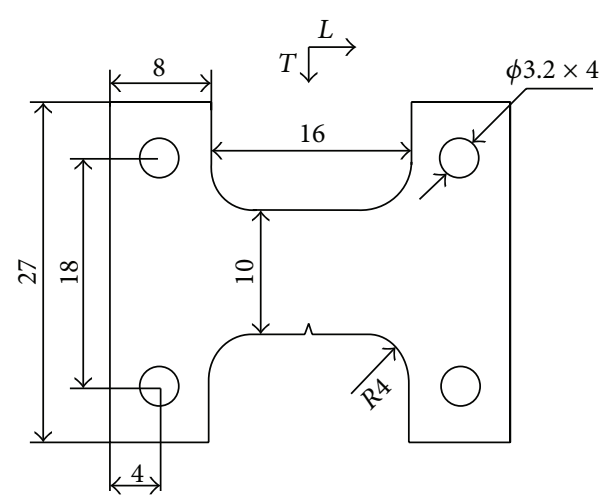

(a)

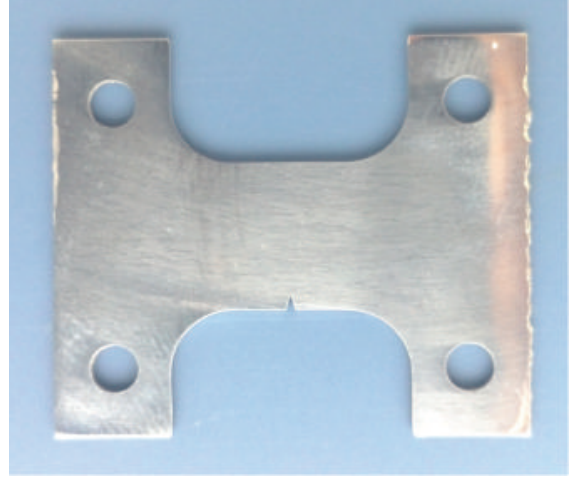

(b)

FIGURE 1: Geometry of the sample: (a) the sample design. (b) Manufactured sample (unit: mm).

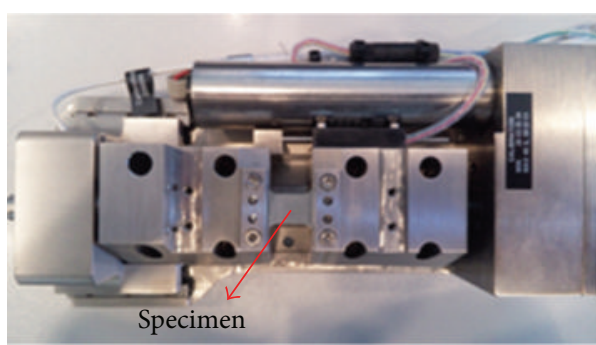

(a)

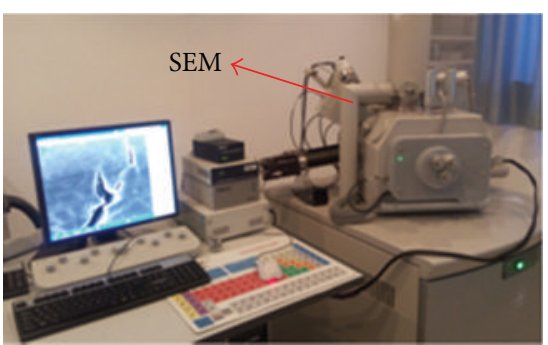

(b)

Figure 2: Experimental platform: (a) in situ testing stage. (b) Quanta 650 SEM.

scale used for the analysis of fatigue crack growth [11] has been developed, and it is different with existing cycle-based method for improving the accuracy. The advantage of this method [12] is that it could be used for analyzing the crack growth behavior at any time instant during one loading cycle.

With regard to the high strength aluminium alloy, the fatigue fracture is the result of damage accumulation formulated by different loading cycles [13-15], and the behavior of fatigue crack growth within one loading cycle determines the service life of 7050-T7451 aluminum alloy. Therefore, researching the damage deformation in smaller time scale is important for mastering the fracture mechanism of 7050T7451 aluminum alloy, and it is beneficial for predicting the residual life of the material.

In this paper, the influence of grain boundary on fatigue crack growth of 7050-T7451 aluminum alloy has been investigated based on the small time scale method. The interaction between grain boundary and fatigue crack growth was researched in the experiment, such as retardation effect on the fatigue crack growth, as well as the behavior of unstable fatigue crack growth within one loading cycle; the result could provide the basis for the optimization and life prediction of 7050-T7451 aluminum alloy.

\section{Experiment}

As shown in Figure 1, the in situ sample with width $W=$ $27 \mathrm{~mm}$, length $L=32 \mathrm{~mm}$, and thickness $T=0.8 \mathrm{~mm}$ was prepared, and $L-T$ is the sampling direction.
TABLE 1: Mechanical properties of 7050-T7451 aluminum alloy.

\begin{tabular}{lcc}
\hline Tensile strength (MPa) & $\begin{array}{c}\text { Yield strength } \\
(\mathrm{MPa})\end{array}$ & $\begin{array}{c}\text { Young's } \\
\text { modulus (GPa) }\end{array}$ \\
\hline 541 & 476 & 72 \\
\hline
\end{tabular}

The material used in the experiment is 7050-T7451 aluminum alloy, and the material mechanical properties are given in Table 1.

Before the in situ testing, the fatigue precracking was accomplished in the hydraulic testing machine, INSTRON 8801 , and the maximum length of precrack is $1 \mathrm{~mm}$. After the precracking testing, the metallographic treatment was applied on the specimen, and the etching agent is Graff Sargent solution ( $1 \mathrm{~mL} \mathrm{HF}, 16 \mathrm{~mL} \mathrm{HNO}_{3}, 3 \mathrm{~g} \mathrm{CrO}_{3}$, and $83 \mathrm{~mL}$ $\mathrm{H}_{2} \mathrm{O}$ ).

\section{Results and Discussion}

As shown in Figure 2(a), the sample was clamped in the in situ testing stage (Deben 2000), and the maximum loading of stage is $2 \mathrm{KN}$. The testing stage was installed in Quanta 650 scanning electron microscope (SEM) as shown in Figure 2(b), and the chamber pressure is less than $3 \times 10^{-2} \mathrm{~Pa}$.

Fatigue loading with constant amplitude was applied on the specimen. The stress ratio $(R)$ is 0.1 and the maximum loading is 1750 N. From the SEM, it was observed that the fatigue crack began to grow stably when the loading cycles 


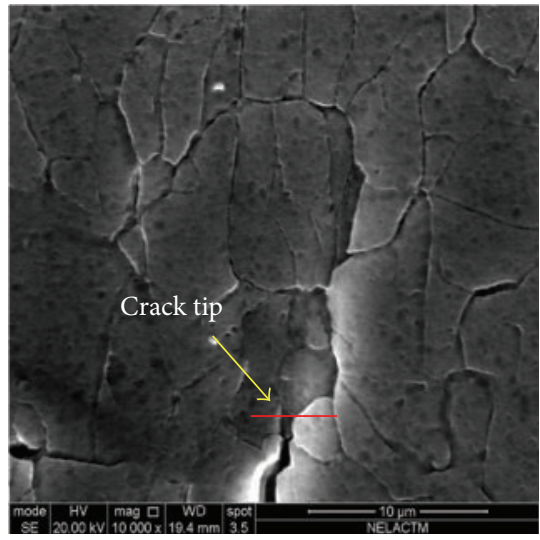

(a)

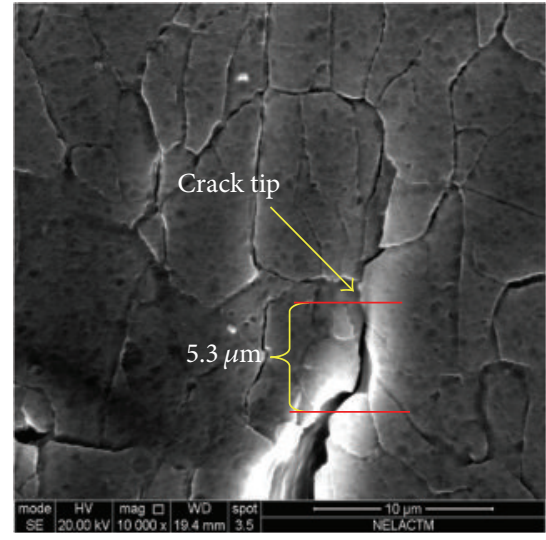

(b)

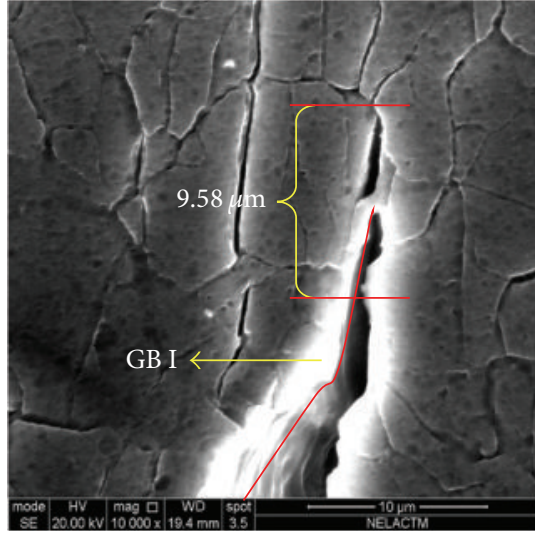

(c)

FIGURE 3: Micromorphology of fatigue crack: (a) at 40 cycles, (b) at 50 cycles, and (c) at 65 cycles.

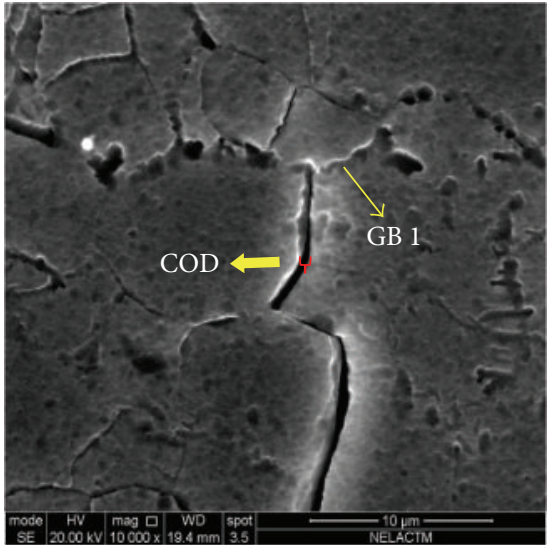

(a)

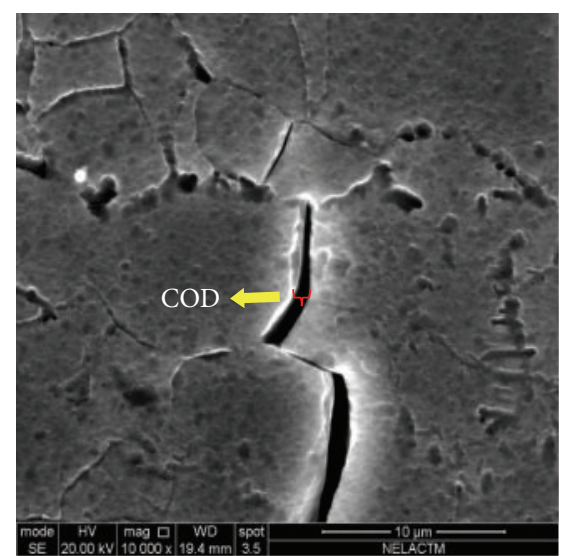

(b)

FIGURE 4: Micromorphology of fatigue crack: (a) at 77 cycles and (b) at 99 cycles.

arrived at 40 , and the micromorphology of fatigue crack from 40 cycles to 65 cycles is shown in Figure 3.

It can be seen that the fatigue crack kept stable growth from 40 cycles to 65 cycles from Figure 3. When the fatigue crack propagates along grain boundary I (GB I), the mean fatigue crack growth rate is $5.85 \times 10^{-4} \mathrm{~mm} / \mathrm{N}$. As shown in Figure $4(\mathrm{a})$, the fatigue crack tip approached grain boundary 1 (GB 1) at 77 cycles.

From Figure 4(a), it can be seen that the angle between fatigue crack and GB 1 is more than 90 degrees at 77 cycles. When the loading cycle arrives at 99 cycles, the fatigue crack tip still stayed under GB 1 as shown in Figure 4(b). From Figure 4(b), it was observed that the crack opening displacement (COD) further increased at 99 cycles, and the retardation effect of GB 1 on the fatigue crack growth is more obvious.

In the loading stage of 99 cycles, micromorphology of fatigue crack at different loading level is shown in Figure 5.

As shown in Figure 5(a), the fatigue crack tip maintained closure when the loading increased to $540 \mathrm{~N}$. The fatigue crack tip started to open when the loading reached $960 \mathrm{~N}$ as shown in Figure 5(b). From Figures 5(c) and 5(d), it can be seen that the COD increased with the increasing of loading. As shown in Figure 5(d), when the loading reached $1750 \mathrm{~N}$, the COD also achieved the maximum.

From Figure 5, it can be seen that some microcracks appear in front of the main crack, and it mainly initiated in the grain boundary. Under the tensile loading, the front of main crack will become a high stress concentration area. Due to the uncoordinated deformation existing between grain and grain boundary, some grain boundary with weak performance will initiate microcrack in front of the main crack under tensile loading.

In the unloading stage of 99 cycles, micromorphology of fatigue crack at different loading level is shown in Figure 6.

As shown in Figure 6, when the loading decreased from $1380 \mathrm{~N}$ to $540 \mathrm{~N}$, the COD also decreased, and the fatigue crack tip recovered from the opening status to the closure status. From Figure 6(d), it can be seen that the fatigue crack tip had been already closed until the loading was decreased to the minimum. It was obtained that the loading value of crack closure is $540 \mathrm{~N}$ which is lower than that of crack opening. 


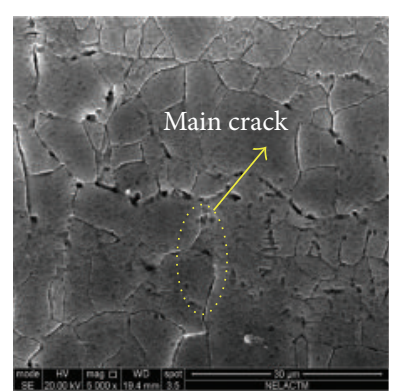

(a)

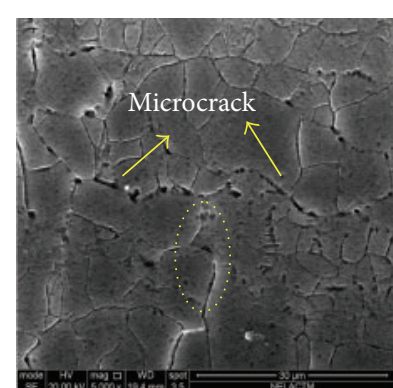

(b)

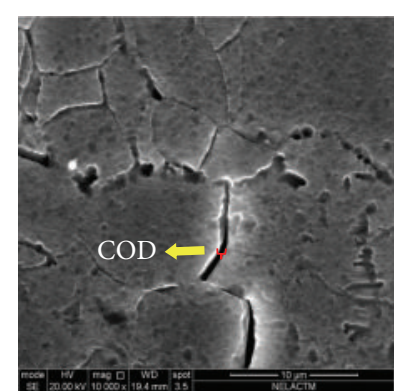

(c)

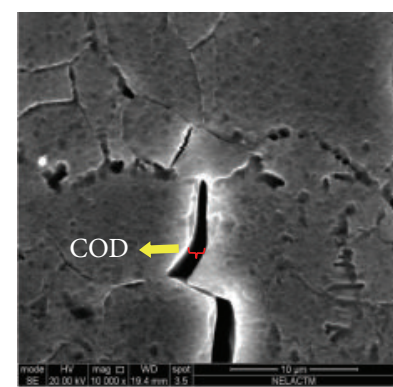

(d)

Figure 5: In the loading stage of 99 cycles, micromorphology of fatigue crack at different loading level: (a) at $540 \mathrm{~N}$, (b) at $960 \mathrm{~N}$, (c) at $1380 \mathrm{~N}$, and (d) at $1750 \mathrm{~N}$.

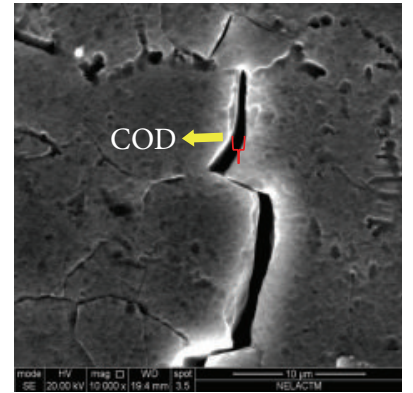

(a)

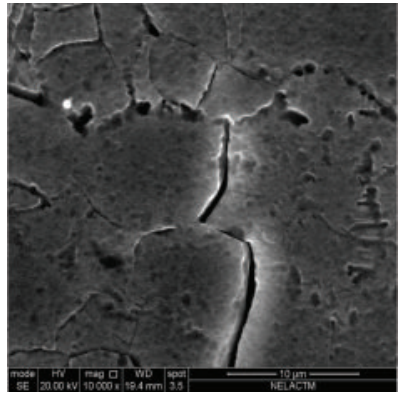

(b)

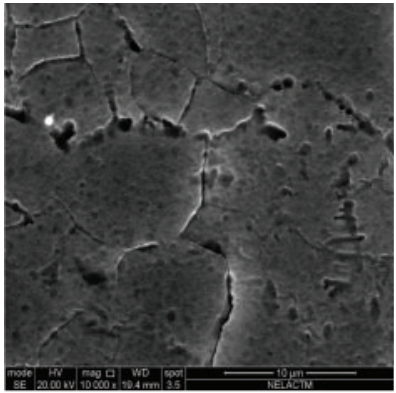

(c)

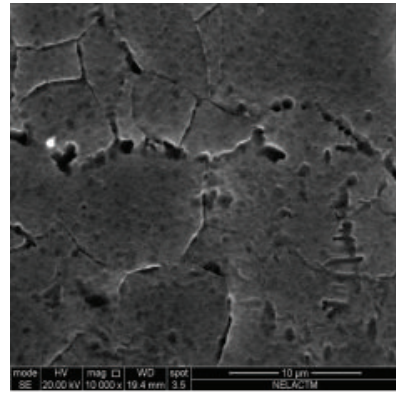

(d)

FIGURE 6: In the unloading stage of 99 cycles, micromorphology of fatigue crack at different loading level: (a) at $1380 \mathrm{~N}$, (b) at $960 \mathrm{~N},(\mathrm{c})$ at $750 \mathrm{~N}$, and (d) at $540 \mathrm{~N}$.

When it reached 111 cycles, the fatigue crack had already been grown rapidly along GB 1 as shown in Figure 7. It can be seen that the fatigue crack growth was retarded by GB 1 for 33 cycles since the loading cycles of 77 .

As shown in Figure 7, the fatigue crack had been grown along GB 1 and the crack tip approached Grain 1 at 111 cycles. Meanwhile, two new cracking paths had been developed: the first path is the crack grew along GB 2, and the second path is the crack that passed through GB 3 and grew into Grain 1.

Because the fatigue crack had been retarded by GB 1 from 77 cycles for several loading cycles, large amounts of deformation energy were concentrated in front of the crack tip. When the energy reached the maximum, the fatigue crack tip will be suddenly opened and the fatigue crack grew along GB 1 promptly. The fatigue crack was able to pass through GB 3 and grow into Grain 1 by the driving of released energy; meanwhile, the remaining energy drove the fatigue crack to grow along GB 2.

In the loading stage of 112 cycles, micromorphology of fatigue crack at different loading level is shown in Figure 8.

From Figures 8(a) and 8(b), it can be seen that the fatigue crack tip remained closed when the loading value is less than 700 N. As shown in Figure 8(c), when the loading reached $700 \mathrm{~N}$, the fatigue crack tip started to open. From Figures $8(\mathrm{~d})$ and $8(\mathrm{e})$, it can be seen that the COD increased with the increment of the loading, and the fracture of GB 4 could be observed in front of the crack tip.

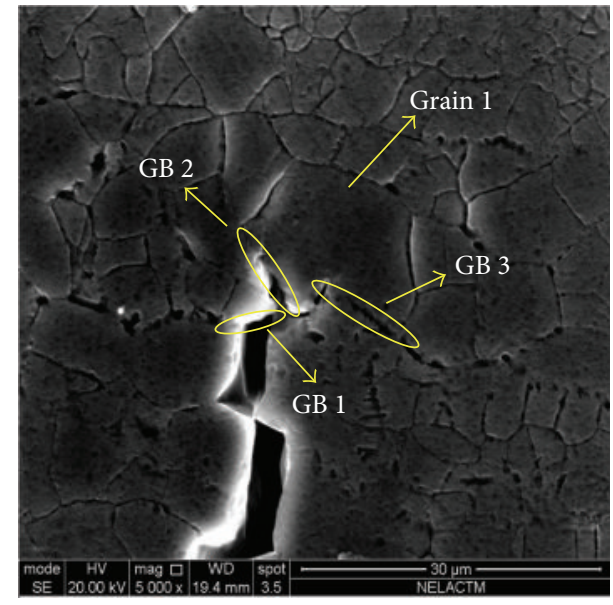

FIGURE 7: Micromorphology of fatigue crack at 111 cycles.

As shown in Figures $8(\mathrm{f})$ and $8(\mathrm{~g})$, when the loading reached $1225 \mathrm{~N}$, the tendency that the crack would grow along GB 2 and connect with GB 4 is more obvious. From Figure $8(\mathrm{~h})$, it can be seen that the COD had been achieved to the maximum when the loading reached $1750 \mathrm{~N}$, and it presented a tendency that the crack tip would be soon connected with GB 4. 


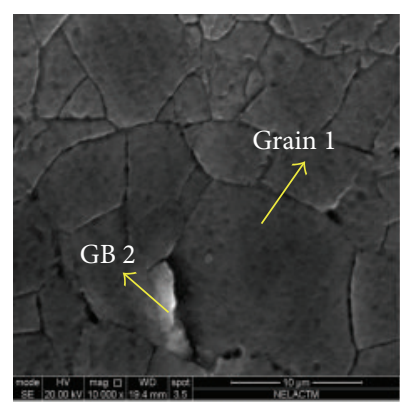

(a)

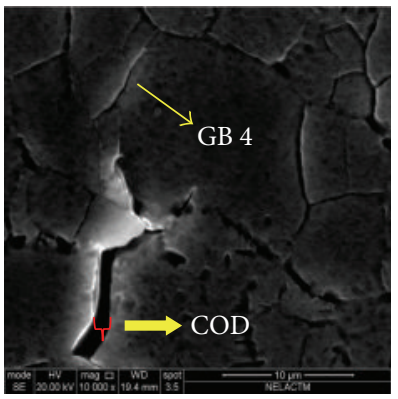

(e)

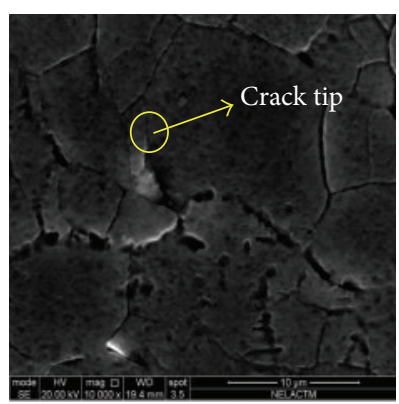

(b)

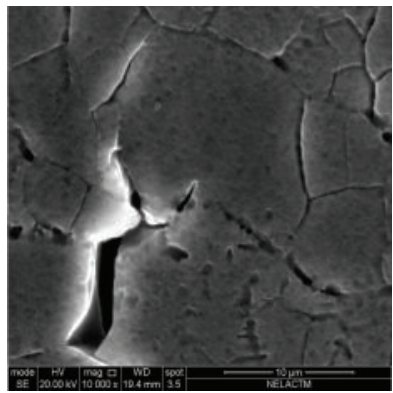

(f)

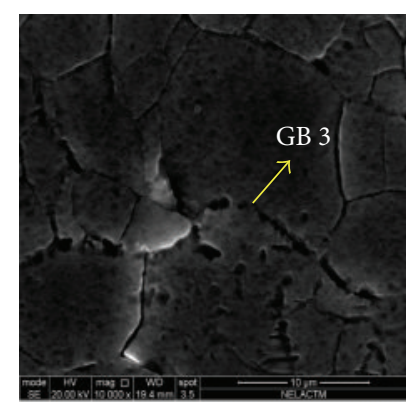

(c)

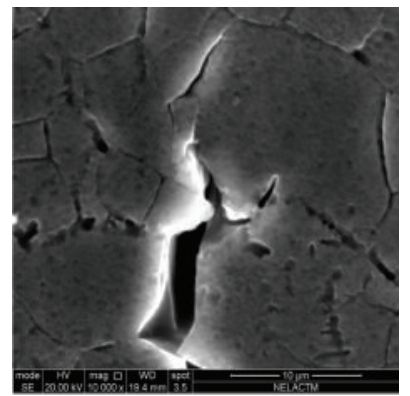

(g)

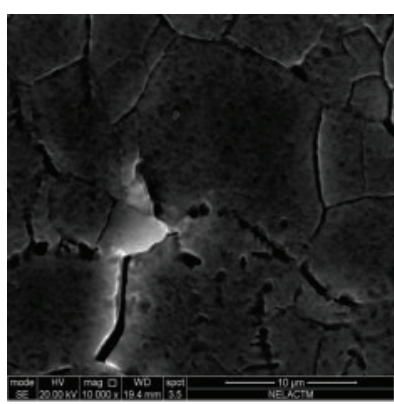

(d)

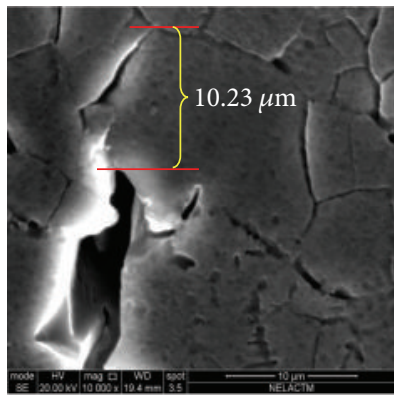

(h)

FIGURE 8: In the loading stage of 112 cycles, micromorphology of fatigue crack at different loading level: (a) at $175 \mathrm{~N},(\mathrm{~b})$ at $525 \mathrm{~N}$, (c) at $700 \mathrm{~N}$, (d) at $875 \mathrm{~N},(\mathrm{e})$ at $1050 \mathrm{~N},(\mathrm{f})$ at $1225 \mathrm{~N},(\mathrm{~g})$ at $1400 \mathrm{~N}$, and (h) at $1750 \mathrm{~N}$.

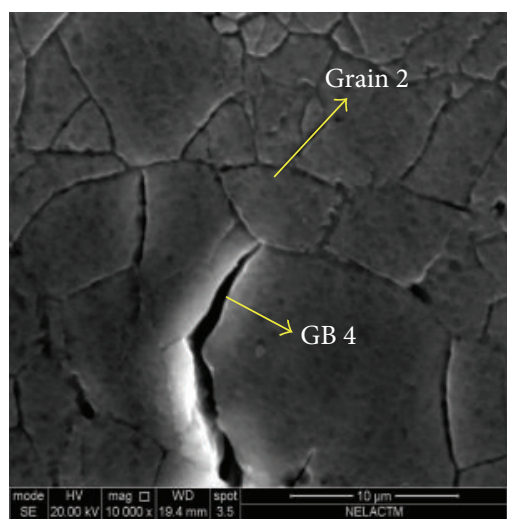

(a)

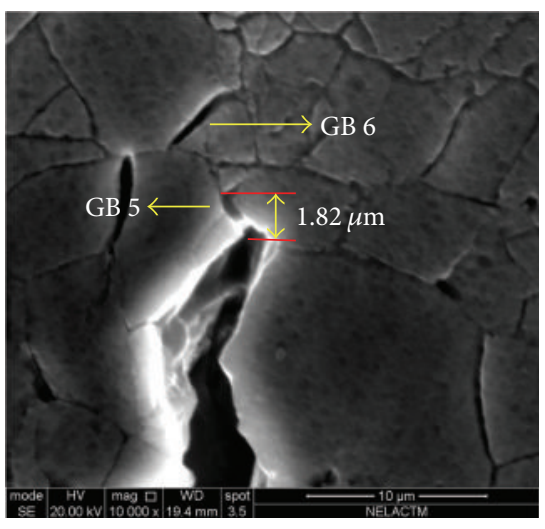

(b)

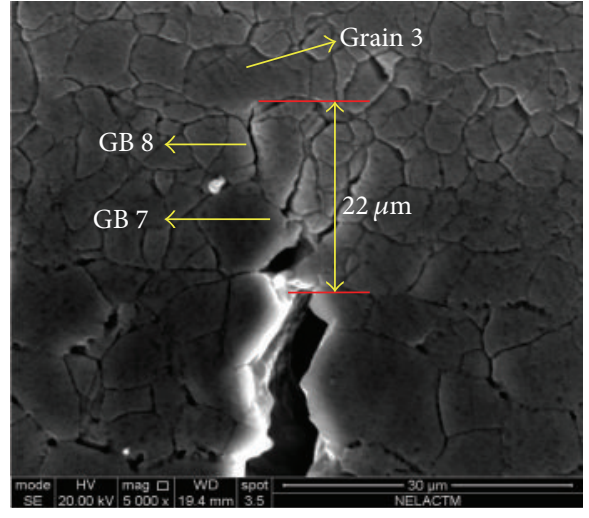

(c)

Figure 9: Micromorphology of fatigue crack at different loading cycles: (a) at 114 cycles, (b) at 116 cycles, and (c) at 119 cycles.

After two loading cycles, the micromorphology of fatigue crack at 114 cycles is shown in Figure 9(a).

As shown in Figure 9(a), the fatigue crack tip had been connected with GB 4 at 114 cycles, and the crack tip approached Grain 2 at present. It was obtained that the fatigue crack growth rate is $3.41 \times 10^{-3} \mathrm{~mm} / \mathrm{N}$ when the fatigue crack propagates along GB 4 . When it reached 116 cycles, it can be seen that the fatigue crack grew along GB 5 as shown in Figure 9(b). The increment of the length of the fatigue crack is 1.82 um between 114 and 116 cycles, and the fracture of GB 6 could be observed. It was obtained that the fatigue crack growth rate is $9.1 \times 10^{-4} \mathrm{~mm} / \mathrm{N}$ when the fatigue crack propagates along GB 5. From Figure 9(c), it can be seen that the fatigue crack had been connected with GB 6 when the loading cycle reached 119, and the fatigue crack tip entered into Grain 3 at present. It is obvious that from 116 to 119 cycles, the increment of the length of the fatigue crack is $22 \mathrm{um}$. It was obtained that the fatigue crack growth rate is $7.3 \times 10^{-3} \mathrm{~mm} / \mathrm{N}$ when the fatigue crack propagates along GB 6 and GB 8.

Micromorphology of fatigue crack from 126 cycles to 131 cycles is shown in Figure 10.

As shown in Figure 10(a), the increment of fatigue crack is $5 \mathrm{um}$ in Grain 3 from 119 cycles to 126 cycles. Meanwhile, the fracture of GB 9 could be observed in front of Grain 3. As shown in Figure 10(b), the fatigue crack further grew at 129 cycles, and the fatigue crack tip opening increased. 


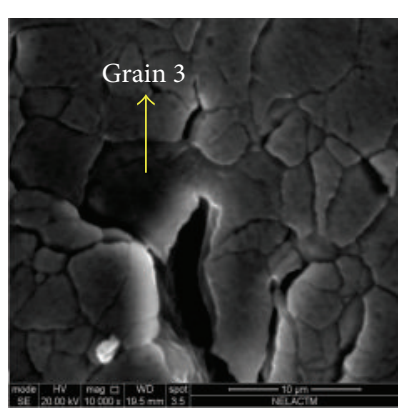

(a)

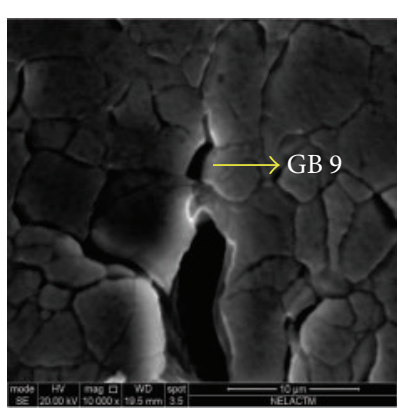

(b)

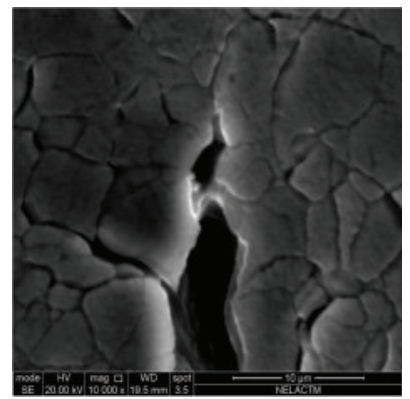

(c)

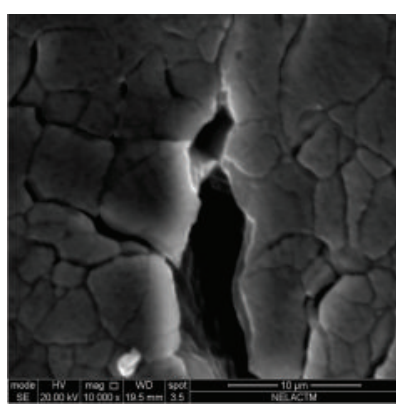

(d)

Figure 10: Micromorphology of fatigue crack at different loading cycles: (a) at 126 cycles, (b) at 129 cycles, (c) at 130 cycles, and (d) at 131 cycles.

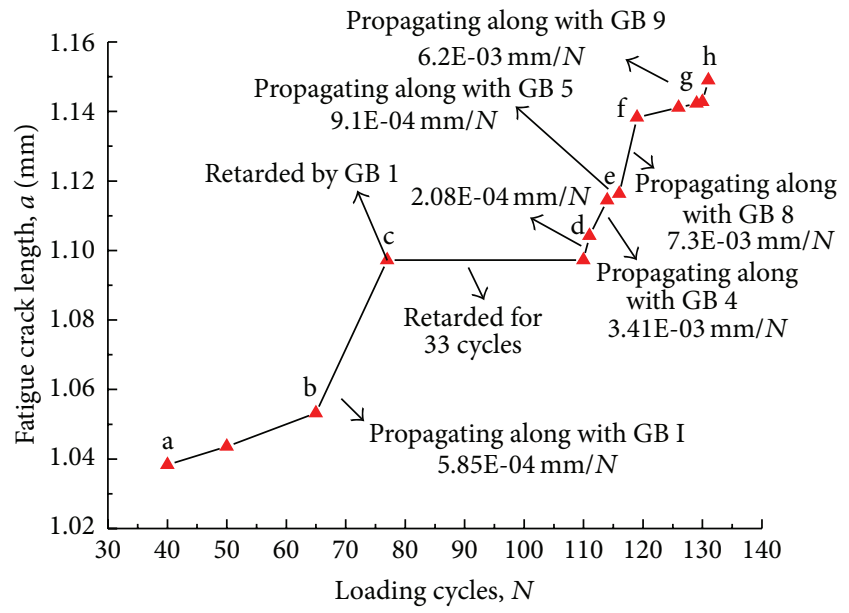

FIGURE 11: Increment of fatigue crack length with the change of loading cycles.

When the loading cycle reached 130, GB 9 was fractured further and the fatigue crack tip approached GB 9. From Figure $10(d)$, it can be seen that the fatigue crack tip had completely passed through Grain 3 and it was connected with GB 9.

The change of fatigue crack length with the loading cycles from 40 cycles to 131 cycles is shown in Figure 11.

It can be seen that the fatigue crack growth rate is different between different loading cycles. The increment of fatigue crack is the minimum from 77 cycles to 111 cycles in the experiment and the fatigue crack growth rate is $2.08 \times$ $10^{-4} \mathrm{~mm} / \mathrm{N}$. The retardation of fatigue crack growth since 77 cycles is mainly caused by the impediment of grain boundary (GB I). The fatigue crack growth will be retarded by the grain boundary when the angle between fatigue crack and grain boundary is greater than 90 degrees in 7050-T7451 aluminum alloy.

The fatigue crack growth is the fastest from 116 cycles to 119 cycles, and the fatigue crack growth rate is $7.3 \times$ $10^{-3} \mathrm{~mm} / N$. The following is $6.2 \times 10^{-3} \mathrm{~mm} / \mathrm{N}$ from 130 cycles to 131 cycles. The rapid growth of fatigue crack is mainly caused by the bridge linked mechanisms between grain boundary and fatigue crack. During the fatigue loading of 7050-T7451 aluminum alloy, the grain boundary is prone to fracture. When the fatigue crack tip connected with the grain boundary, the fatigue crack presented fast unstable growth, which led to the life reduction of 7050-T7451 aluminum alloy.

\section{Conclusions}

(1) When 7050-T7451 aluminum alloy is under the fatigue loading with constant amplitude, the fatigue crack growth will be retarded by the grain boundary. When the angle between the fatigue crack and the grain boundary is greater than 90 degrees, the retardation phenomenon is more obvious.

(2) The fatigue crack tip is not able to open until the loading reached $55 \%$ of the maximum value when the fatigue crack was retarded by the grain boundary. The fatigue crack had been completely closed when the loading is not reduced to the maximum value, and it is observed that the crack opening loading is higher than the crack closure loading.

(3) When the 7050-T7451 aluminum alloy suffered from fatigue loading with constant amplitude, a behavior of unstable fatigue crack growth could be observed in 7050-T7451 aluminum alloy, which related to the bridge linked mechanism of fatigue crack. The grain boundary was prone to fracture during fatigue loading of 7050-T7451 aluminum alloy, and the fractured GB became the best path for the fatigue growth. During the fatigue loading stage, the fatigue crack tends to grow in the direction of cracking grain boundary, and it will be connected with fractured GB eventually, which led to the fast growth of fatigue crack.

\section{Competing Interests}

The authors declare that they have no competing interests.

\section{Acknowledgments}

This research is supported by two National technical infrastructure projects, the first Project no. is JSZL 2014601B001 and the second Project no. is JSZL 2014601B004. Special thanks go to Professor Dai for his assistance in the revision of paper. 


\section{References}

[1] A. W. Mello, A. Nicolas, R. A. Lebensohn, and M. D. Sangid, "Effect of microstructure on strain localization in a 7050 aluminum alloy: comparison of experiments and modeling for various textures," Materials Science and Engineering: A, vol. 661, pp. 187-197, 2016.

[2] D. C. C. Magalhães, M. F. Hupalo, and O. M. Cintho, "Natural aging behavior of AA7050 Al alloy after cryogenic rolling," Materials Science and Engineering A, vol. 593, pp. 1-7, 2014.

[3] N. Kamp, N. Gao, M. J. Starink, and I. Sinclair, "Influence of grain structure and slip planarity on fatigue crack growth in low alloying artificially aged 2xxx aluminium alloys," International Journal of Fatigue, vol. 29, no. 5, pp. 869-878, 2007.

[4] M. Scharnweber, W. Tirschler, V. Mikulich, S. Jacob, C.-G. Oertel, and W. Skrotzki, "Influence of crack length and grain boundaries on the propagation rate of short cracks in austenitic stainless steel," Scripta Materialia, vol. 67, no. 7-8, pp. 677-680, 2012.

[5] C. Holzapfel, W. Schäf, M. Marx, H. Vehoff, and F. Mücklich, "Interaction of cracks with precipitates and grain boundaries: understanding crack growth mechanisms through focused ion beam tomography," Scripta Materialia, vol. 56, no. 8, pp. 697700, 2007.

[6] D. Terentyev and F. Gao, "Blunting of a brittle crack at grain boundaries: an atomistic study in BCC Iron," Materials Science and Engineering A, vol. 576, pp. 231-238, 2013.

[7] P. Wang and J. X. Dong, "Effect of the grain boundary carbide on the crack propagation rates of GH864 alloy," Rare Metal Materials and Engineering, vol. 43, no. 11, pp. 2723-2727, 2014.

[8] W. Y. Zhang, "Study on the low cycle fatigue fracture in TA5 titanium alloy plates," Rare Metal Materials and Engineering, vol. 27, no. 3, pp. 156-160, 1998.

[9] K. Dám, P. Lejček, and A. Michalcová, "In situ TEM investigation of microstructural behavior of superplastic Al-Mg-Sc alloy," Materials Characterization, vol. 76, pp. 69-75, 2013.

[10] C. Meng, D. Zhang, L. Zhuang, and J. Zhang, "Correlations between stress corrosion cracking, grain boundary precipitates and $\mathrm{Zn}$ content of Al-Mg-Zn alloys," Journal of Alloys and Compounds, vol. 655, Article ID 35434, pp. 178-187, 2016.

[11] Z. Lu and Y. Liu, "Small time scale fatigue crack growth analysis," International Journal of Fatigue, vol. 32, no. 8, pp. 1306-1321, 2010.

[12] W. Zhang and Y. Liu, "Investigation of incremental fatigue crack growth mechanisms using in situ SEM testing," International Journal of Fatigue, vol. 42, pp. 14-23, 2012.

[13] A. Pineau, D. L. McDowell, E. P. Busso, and S. D. Antolovich, "Failure of metals II: fatigue," Acta Materialia, vol. 107, pp. 484507, 2015.

[14] B. Sun, Y.-L. Xu, and Z. Li, "Multi-scale model for linking collective behavior of short and long cracks to continuous average fatigue damage," Engineering Fracture Mechanics, vol. 157, pp. 141-153, 2015.

[15] J. Schijve, "The application of small overloads for fractography of small fatigue cracks initiated under constant-amplitude loading," International Journal of Fatigue, vol. 70, pp. 63-72, 2015. 

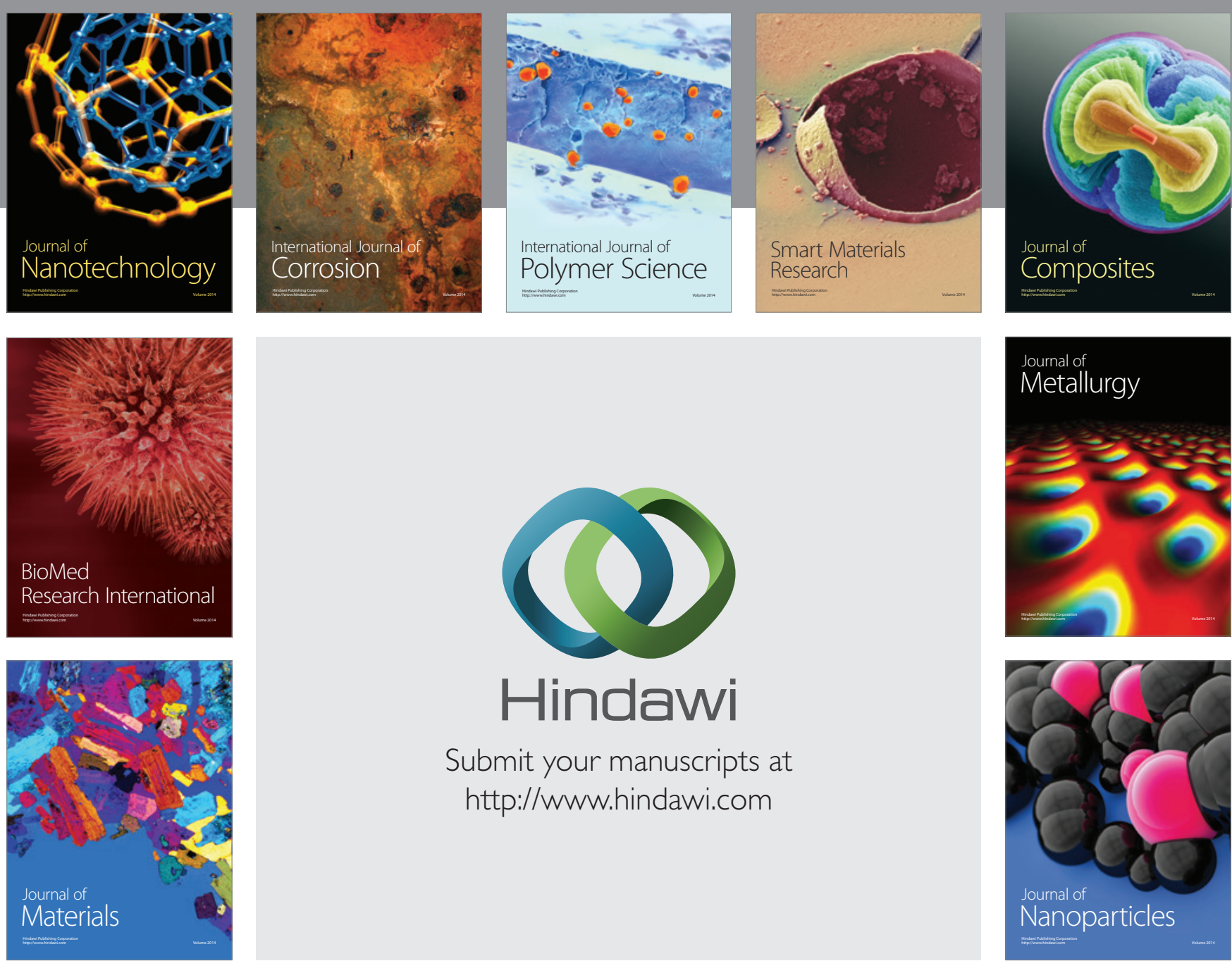

\section{Hindawi}

Submit your manuscripts at

http://www.hindawi.com

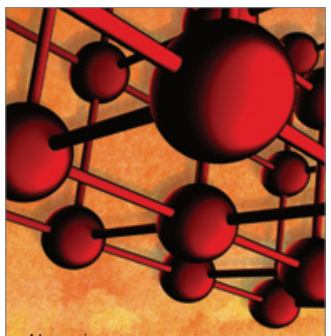

Materials Science and Engineering
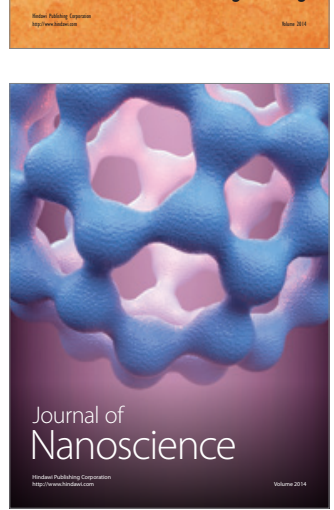
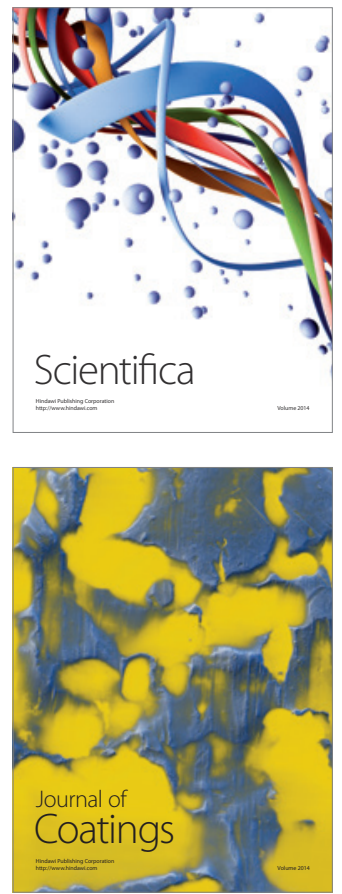
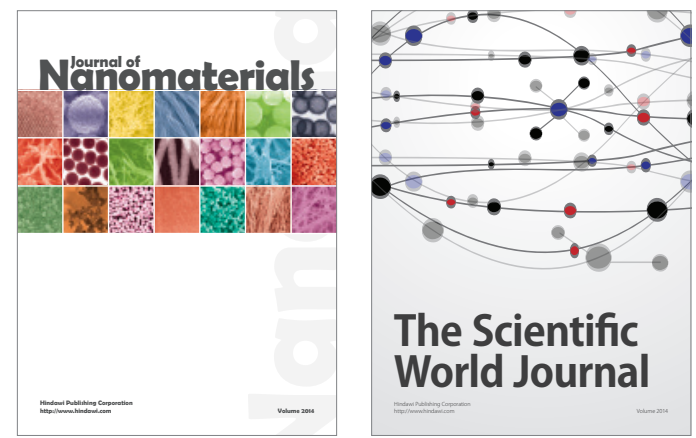

The Scientific World Journal
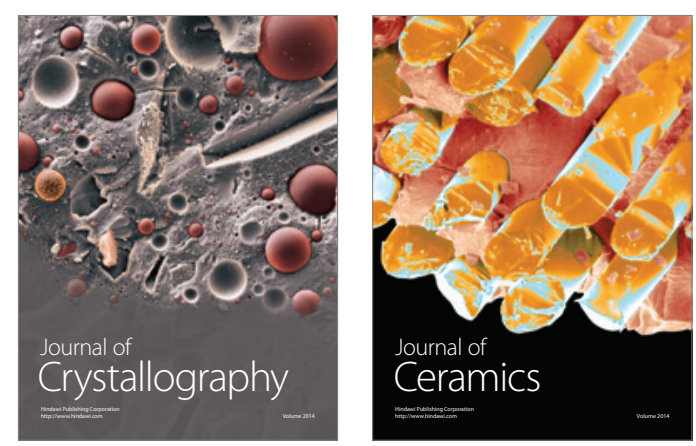
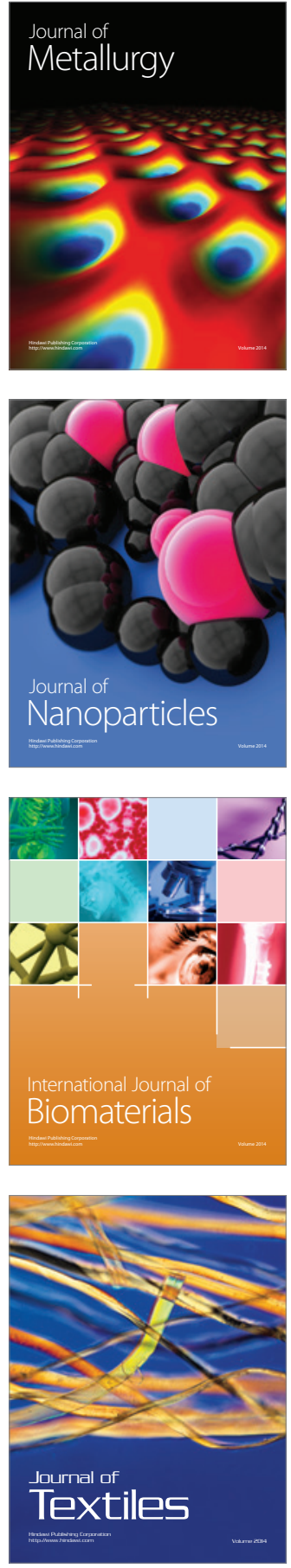